\title{
REGIONAL HAZARD ANALYSIS FOR USE IN VULNERABILITY AND RISK ASSESSMENT
}

\author{
Fotios Maris ${ }^{1}$, KYriaki KitIKIDOU ${ }^{1}$, SPYRIDON PAPARrizos ${ }^{2}$, \\ Konstantinos Karagiorgos ${ }^{3}$, Simeon Potouridis ${ }^{1}$, Sven Fuchs ${ }^{3}$

\begin{abstract}
${ }^{1}$ Democritus University, Department of Forestry and Management of the Environment and Natural Resources, Orestiada, Greece

${ }^{2}$ Faculty of Environment and Natural Resources, Albert-Ludwigs-University of Freiburg, Germany ${ }^{3}$ University of Natural Resources and Life Sciences, Institute of Mountain Risk Engineering, Vienna, Austria
\end{abstract}

Manuscript received: April 11, 2015

Revised version: August 5, 2015

\begin{abstract}
Maris F., Kitikidou K., Paparrizos S., Karagiorgos K., Potouridis S., Fuchs S., 2015. Regional hazard analysis for use in vulnerability and risk assessment. Quaestiones Geographicae 34(3), Bogucki Wydawnictwo Naukowe, Poznań, pp. 77-84, 3 figs, 6 tables. DOI 10.1515/quageo-2015-0026, ISSN 0137-477X.

AвSTRACT: A method for supporting an operational regional risk and vulnerability analysis for hydrological hazards is suggested and applied in the Island of Cyprus. The method aggregates the output of a hydrological flow model forced by observed temperatures and precipitations, with observed discharge data. A scheme supported by observed discharge is applied for model calibration. A comparison of different calibration schemes indicated that the same model parameters can be used for the entire country. In addition, it was demonstrated that, for operational purposes, it is sufficient to rely on a few stations. Model parameters were adjusted to account for land use and thus for vulnerability of elements at risk by comparing observed and simulated flow patterns, using all components of the hydrological model. The results can be used for regional risk and vulnerability analysis in order to increase the resilience of the affected population.
\end{abstract}

KEYWORDS: hazard analysis, operational analysis, risk assessment, vulnerability

Address of the corresponding author: Fotios Maris, Democritus University, Department of Forestry and Management of the Environment and Natural Resources, Orestiada, Greece; e-mail: fmaris@fmenr.duth.gr

\section{Introduction}

Given the conditions of global environmental change such as outlined in the Fifth Assessment Report of the United National Intergovernmental Panel on Climate Change (Stocker et al. 2013), impacts from natural hazards on natural and human systems are manifest world-wide (Field et al. 2014). Therefore, such impacts are the result of both the frequency and magnitude of the environmental hazard and the exposure of the society or elements at risk such as buildings or infrastructure lines. According to Varnes (1984), risk can be defined as the expected degree of loss due to particular natural phenomena of a given magnitude and frequency, and exposure is given by a set of processes and situations emerging from socio-economic, environmental and physical impacts driving vulnerability, sensitivity and resilience of the population at risk. In recent years, the concepts of vulnerability and resilience (again) became popular in environmental hazard and risk management (Parry et al. 2007). Ideas and concepts of vulnerability and resilience are used by various scholars from different scientific disciplines - as well as by practitioners and institutions - and hence are used in multiple disciplinary models underpinning either a technical 
or a social origin of the concept and resulting in a range of paradigms for either a qualitative or quantitative assessment, both scale-dependent. Despite the growing amount of studies recently published (e.g., Menoni et al. 2012, Birkmann et al. 2013) current approaches are still driven by a divide between natural and social sciences, even if some attempts have been made within to bridge this gap (e.g., Fuchs (2009) with respect to vulnerability and Kuhlicke (2013) pointing on resilience). Whereas social scientists tend to view vulnerability and resilience as representing the set of socio-economic factors that determine people's ability to cope with stress or changes (e.g., Field et al. 2012), natural scientists and engineers often view both terms focusing on the likelihood of occurrence of specific hazards, and associated impacts on the built environment (e.g., Papathoma-Köhle et al. 2011). Representatives from each discipline define both vulnerability and resilience in a way which fits to their individual disciplinary purposes. However, efforts to reduce the exposure to hazards and to create disaster-resilient communities require intersections among these different disciplines (Fuchs et al. 2011, Birkmann et al. 2013), since human activity cannot be seen independently from the environmental settings and vice versa. Simultaneously, approaches suitable within the development context may not fit to the climate change context. Acknowledging different roots of disciplinary paradigms, methods determining structural, economic, institutional or social vulnerability and resilience should be inter-woven in order to enhance our understanding of vulnerability and resilience, and to adapt to ongoing global change processes. Therefore, there is a need to expand our vision on hazard and risk management integrating adaptation and mitigation approaches into the broader context of related governance arrangements. As such, it is increasingly recognized that disaster risk and threats to human security cannot be reduced by focusing solely on the hazards. The Sendai Framework for Disaster Risk Reduction 2015-2030, which was formulated at the Third UN World Conference on Disaster Reduction in 2015, underlines that the starting point for reducing disaster risk and for promoting a culture of disaster resilience is the knowledge of the hazards and the physical, social, economic and environmental vulnerabilities to disasters that most societies bear (UN/ISDR 2015). Regional hazard analysis is the starting point of any of such actions.

As indicated by the current scientific consensus, the Mediterranean Basin is considered amongst the geographic regions that are most endangered to climate change, and is expected to have unfavourable climate change effects. Hence, Cyprus is placed in a hot spot and will confront a serious risk for desertification, which is expected to worsen with climate change (Zachariadis 2012). In this paper, we present a regional analysis of hydrological hazards for the island of Cyprus in order to enhance subsequent risk and vulnerability analysis.

\section{Materials and Methods}

\section{Raw data}

Based on the scope of the study, a quantitative approach was applied and data was collected for analysis from two sets of hydrological and meteorological stations (70 and eight stations, respectively) in Cyprus (Fig. 1). The data was provided by the Water Development Department of Cyprus <http://www.moa.gov.cy/moa/wdd/ Wdd.nsf/index_en/index_en?OpenDocument>. The data recorded included:

- for the first set of 70 stations: the area of the watershed, the perimeter of the selected stations, the roundness, the altitude (minimum, maximum, mean), the mean annual precipitation, the mean slope, the length and density of the hydrological network, the land use, and the mean annual flow of water for each station (drainage trend),

- for the second set of eight stations: the minimum and maximum monthly temperatures for the years 1979 to 2009 .

The data showed the intensity of the parameter measured in terms of scale data to reflect the actual effect of the factor on the ground.

\section{Data Manipulations and Operational Analysis}

We applied the parametric analysis system on the data which could indicate the normal distribution based on the central tendencies. Further, 


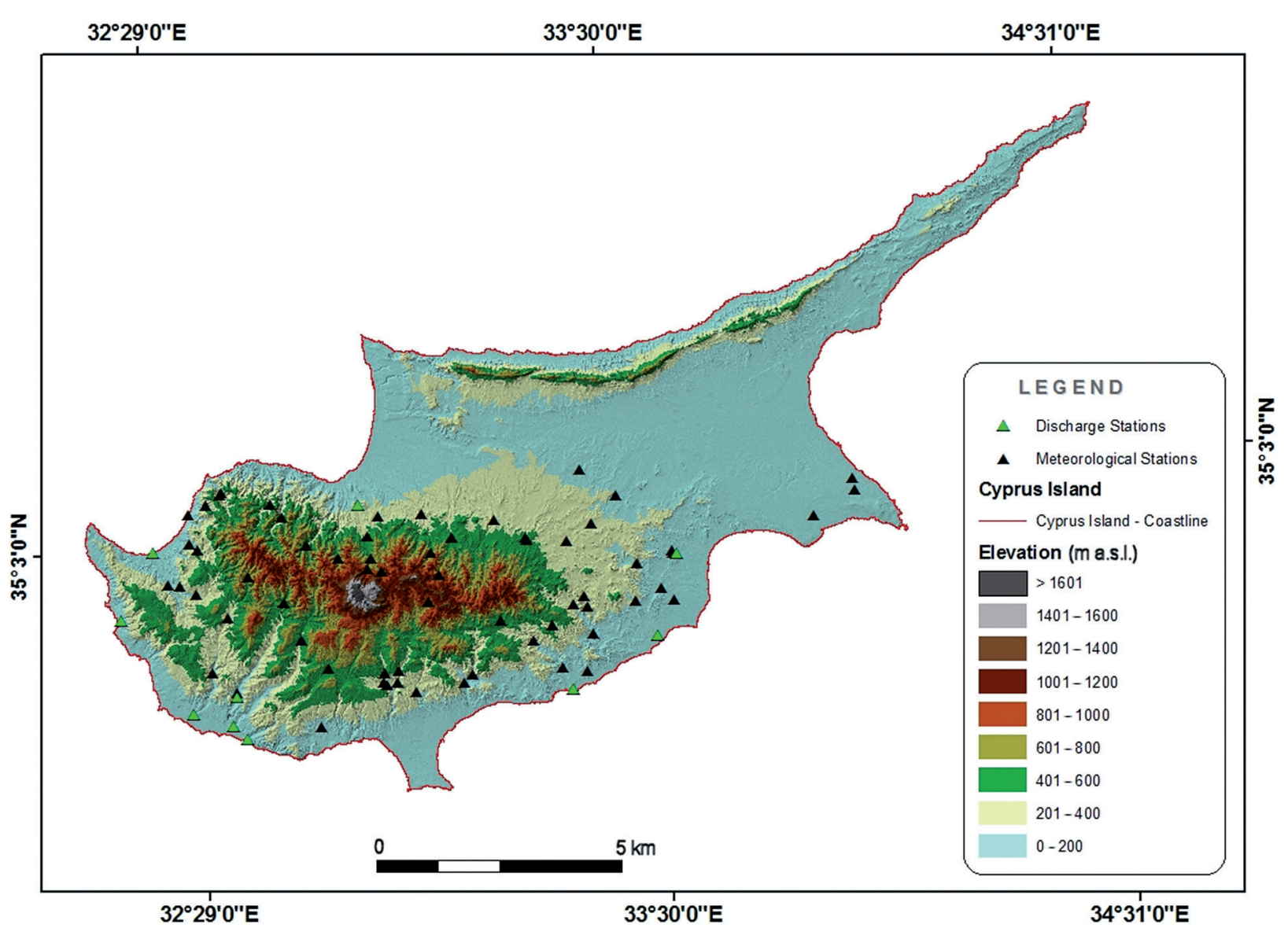

Fig. 1. Cyprus Island map displaying stations position.

we used the non-parametric statistical analysis on the data that could not show the standard distribution from the central tendencies. We used SPSS Modeler v.14.2 which allows data entry, management, processing, analysis and presentation.

Kohonen's algorithm was applied for operational analysis purposes (Kohonen 1982). Kohonen networks are a type of neural network that perform clustering, also known as a k-net or a self-organizing map, and are widely used in hydrology (Govindaraju and Rao 2000). This type of network can be used to cluster the dataset into distinct groups. Records are grouped so that records within a group or cluster tend to be similar to each other, and records in different groups are dissimilar. The basic units are neurons, and they are organized into two layers: the input layer and the output layer (output map). All of the input neurons are connected to all of the output neurons, and these connections have strengths, or weights, associated with them. During training, each unit competes with all of the others to "win" each record.
Initially, all weights are random. When a unit wins a record, its weights (along with those of other nearby units, collectively referred to as a neighborhood) are adjusted to better match the pattern of predictor values for that record. All of the input records are shown, and weights are updated accordingly. This process is repeated many times until the changes become very small. As training proceeds, the weights on the grid units are adjusted so that they form a two-dimensional "map" of the clusters (hence the term self-organizing map). When the network is fully trained, records that are similar should be close together on the output map, whereas records that are vastly different will be far apart.

Unlike most learning methods, Kohonen networks do not use a target field. This type of learning, with no target field, is called unsupervised learning. Instead of trying to predict an outcome, Kohonen nets try to uncover patterns in the set of input fields.

The silhouette measure indicates whether the formation of groups is poor, fair or good, as 
regards the cohesion and the separation (Kaufman and Rousseeuw 2005). A silhouette measure equal to -1 means that all entries are in the wrong group (i.e. wrong pattern), a measure equal to 0 that all entries have the same distance from the centre of the group where they belong and from the centres of the other groups (i.e. no pattern), while a measure equal to 1 means that all entries are in the correct group (i.e. correct pattern).

In order to apply the selected operational analysis technique, we discretized our data, i.e. we reduced the number of values for given continuous attributes by dividing the range of the attribute into intervals (Kurgan and Cios 2001, Ratanamahatana 2003), by using the Categorical Regression CATREG Discretization (IBM 2011).

To make comparisons between k-nets under customary repeated sampling, 250 samples of average size 30 were selected by simple random sampling.

\section{Map Formation}

Following grouping of stations, we displayed them on a map of Cyprus, using their coordinates. As Coordinates Reference System (CRS), Universal Transverse Mercator (UTM) was recorded (WGS 1984; Cyprus Island belongs to UTM $36 \mathrm{~N}$ zone).

\section{Results}

Descriptive statistics for the first set of 70 stations are given in Table 1, while for the second set of eight stations are given in Fig. 2.

For the first set of 70 stations, the average silhouette measure of cohesion and separation was calculated equal to 0.9 , which defines the quality of the model as "Good".

Based on the selected operational technique, the first set of 70 stations forms four groups (Table 2 ), and the most important variable that defined this formation was the minimum altitude. Means for the four groups of stations, for all variables measured, are given in Table 3.

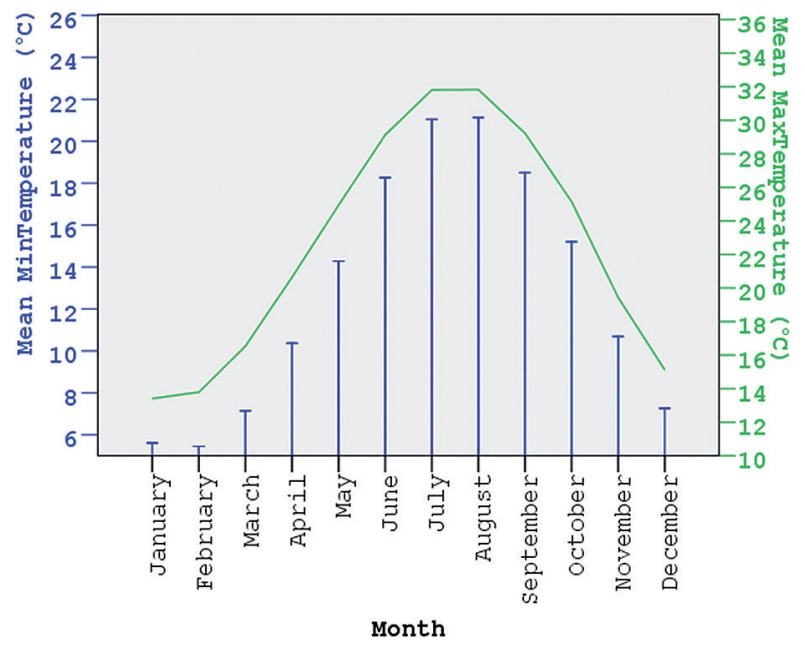

Fig. 2. Mean minimum and maximum temperatures, from measurements from 8 stations, for the years 1979 to 2009 .

Table 1. Decriptive statistics for all variables measured in the first set of 70 stations.

\begin{tabular}{|c|c|c|c|c|c|}
\hline & Variable & Mean & $\begin{array}{l}\text { Standard } \\
\text { deviation }\end{array}$ & Minimum & Maximum \\
\hline & ea $\left(\mathrm{km}^{2}\right)$ & 132.08 & 146.87 & 19.27 & 867.14 \\
\hline & imeter $(\mathrm{km})$ & 62.45 & 32.49 & 27.02 & 207.35 \\
\hline & undness & 1.83 & 0.77 & 0.51 & 4.48 \\
\hline & ximum altitude $(\mathrm{m})$ & 839.47 & 477.97 & 68.00 & 1945.00 \\
\hline & an altitude $(\mathrm{m})$ & 269.75 & 184.58 & 18.85 & 815.57 \\
\hline & nimum altitude $(\mathrm{m})$ & 2.06 & 4.30 & 0.00 & 26.00 \\
\hline & an annual precipitation $(\mathrm{mm})$ & 509.11 & 129.86 & 329.92 & 827.62 \\
\hline & an slope (\%) & 7.53 & 4.17 & 0.59 & 17.72 \\
\hline & twork's length $(\mathrm{km})$ & 276.40 & 323.92 & 16.82 & 1630.44 \\
\hline & twork's density $\left(\mathrm{km} / \mathrm{km}^{2}\right)$ & 2.16 & 1.28 & 0.12 & 4.94 \\
\hline & an annual flow $\left(\mathrm{m}^{3} / \mathrm{sec}\right)$ & 26.12 & 20.72 & 5.72 & 173.24 \\
\hline & Broad-leaved forest + Mixed forest + Coniferous forest $(\%)$ & 20.06 & 20.93 & 0.00 & 81.10 \\
\hline 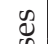 & Transitional woodland-shrub (\%) & 10.29 & 9.59 & 0.51 & 36.17 \\
\hline 胥 & $\begin{array}{l}\text { Land principally occupied by agriculture. with significant } \\
\text { areas of natural vegetation }(\%)\end{array}$ & 44.54 & 20.36 & 6.51 & 90.39 \\
\hline ב & Natural grasslands (\%) & 3.22 & 4.62 & 0.00 & 19.25 \\
\hline & Sclerophyllous vegetation (\%) & 21.88 & 16.67 & 0.03 & 83.88 \\
\hline
\end{tabular}


Table 2. Grouping of the first set of 70 stations.

\begin{tabular}{|c|c|c|}
\hline $\begin{array}{c}\text { Group } \\
\text { of stations }\end{array}$ & $\begin{array}{c}\text { Percent } \\
\text { of stations }\end{array}$ & $\begin{array}{c}\text { Kohonen pseu- } \\
\text { do-coordinates }\end{array}$ \\
\hline 1 & 7.14 & $\mathrm{X}=0, \mathrm{Y}=0$ \\
\hline 2 & 17.14 & $\mathrm{X}=0, \mathrm{Y}=2$ \\
\hline 3 & 22.86 & $\mathrm{X}=2, \mathrm{Y}=2$ \\
\hline 4 & 52.86 & $\mathrm{X}=3, \mathrm{Y}=0$ \\
\hline
\end{tabular}

Table 4. Grouping of the second set of 8 stations.

\begin{tabular}{|c|c|c|}
\hline Group & $\begin{array}{c}\text { Percent } \\
\text { of measurements }\end{array}$ & $\begin{array}{c}\text { Kohonen pseu- } \\
\text { do-coordinates }\end{array}$ \\
\hline 1 & 16.7 & $\mathrm{X}=0, \mathrm{Y}=0$ \\
\hline 2 & 25.1 & $\mathrm{X}=0, \mathrm{Y}=2$ \\
\hline 3 & 8.3 & $\mathrm{X}=1, \mathrm{Y}=2$ \\
\hline 4 & 8.2 & $\mathrm{X}=2, \mathrm{Y}=0$ \\
\hline 5 & 16.7 & $\mathrm{X}=3, \mathrm{Y}=0$ \\
\hline 6 & 25.0 & $\mathrm{X}=3, \mathrm{Y}=2$ \\
\hline
\end{tabular}

Table 3. Means for all variables measured in the 4 groups of 70 stations.

\begin{tabular}{|c|c|c|c|c|c|}
\hline \multirow{2}{*}{\multicolumn{2}{|c|}{ Variable }} & \multicolumn{4}{|c|}{ Group } \\
\hline & & 1 & 2 & 3 & 4 \\
\hline \multicolumn{2}{|c|}{ Area $\left(\mathrm{km}^{2}\right)$} & 119.59 & 107.37 & 170.81 & 125.03 \\
\hline \multicolumn{2}{|c|}{ Perimeter $(\mathrm{km})$} & 56.07 & 61.66 & 68.42 & 60.99 \\
\hline \multicolumn{2}{|c|}{ Roundness } & 2.02 & 1.64 & 1.98 & 1.79 \\
\hline \multicolumn{2}{|c|}{ Maximum altitude $(\mathrm{m})$} & 1009.20 & 1019.92 & 1076.63 & 655.46 \\
\hline \multicolumn{2}{|c|}{ Mean altitude $(\mathrm{m})$} & 366.04 & 324.50 & 359.57 & 200.14 \\
\hline \multicolumn{2}{|c|}{ Minimum altitude (m) } & 4.00 & 1.00 & 7.00 & 0.00 \\
\hline \multicolumn{2}{|c|}{ Mean annual precipitation (mm) } & 572.81 & 556.27 & 552.77 & 466.33 \\
\hline \multicolumn{2}{|c|}{ Mean slope $(\%)$} & 9.95 & 8.69 & 8.39 & 6.45 \\
\hline \multicolumn{2}{|c|}{ Network's length $(\mathrm{km})$} & 355.28 & 307.79 & 352.60 & 222.61 \\
\hline \multicolumn{2}{|c|}{ Network's density $\left(\mathrm{km} / \mathrm{km}^{2}\right)$} & 2.82 & 2.75 & 2.56 & 1.70 \\
\hline \multicolumn{2}{|r|}{ Mean annual flow $\left(\mathrm{m}^{3} / \mathrm{sec}\right)$} & 28.37 & 27.23 & 37.20 & 20.67 \\
\hline \multirow{5}{*}{ 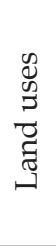 } & Broad-leaved forest + Mixed forest + Coniferous forest $(\%)$ & 28.92 & 27.14 & 20.22 & 16.49 \\
\hline & Transitional woodland-shrub (\%) & 11.71 & 9.30 & 10.26 & 10.43 \\
\hline & $\begin{array}{l}\text { Land principally occupied by agriculture. with signifi- } \\
\text { cant areas of natural vegetation }(\%)\end{array}$ & 40.98 & 37.28 & 40.23 & 49.24 \\
\hline & Natural grasslands (\%) & 3.67 & 3.00 & 4.06 & 2.86 \\
\hline & Sclerophyllous vegetation (\%) & 14.73 & 23.24 & 25.21 & 20.97 \\
\hline
\end{tabular}

For the second set of eight stations, the average silhouette measure of cohesion and separation was calculated equal to 0.4 , which defines the quality of the model as "Fair".

Based on the selected operational technique, the temperature measurements from the eight stations are classified in six groups (Table 4), and the most important variable that defined this formation was the month. Means for these 6 groups, for both temperatures measured, are given in Table 5.

Finally, the comparison of different calibration schemes (repeated random sampling) indicated that the same model parameters can be used (extrapolated) for the entire island. In addition, it was demonstrated that, for operational purposes, it is sufficient to rely on a fewer stations than the 70 of the first set (results were similar with 65 or 60 , randomly selected, stations). Original classification of the 70 stations dataset that was used for repeated random sampling and extrapolation purposes is given in Table 6.
Table 5. Means for temperatures measured in the 6 groups of 8 stations.

\begin{tabular}{|c|c|c|c|c|c|c|}
\hline \multirow{2}{*}{ Temperature } & \multicolumn{7}{|c|}{ Group } \\
\cline { 2 - 7 } & 1 & 2 & 3 & 4 & 5 & 6 \\
\hline Minimum & 15.79 & 13.65 & 14.28 & 7.26 & 11.90 & 12.50 \\
\hline Maximum & 26.27 & 23.67 & 24.94 & 15.12 & 21.52 & 21.61 \\
\hline
\end{tabular}

Following grouping of the first set of 70 stations, we displayed on a map, showing the areas with common characteristics in different colors (Fig. 3). Combined with socio-economic factors, this map can be a very useful tool in risk and vulnerability assessment.

\section{Discussion - Conclusion}

Due to rapid developing computational technology, large datasets for composite ecological systems have been increasingly available. Life science researchers are collecting massive data, and the assumption is that something in the data 
Table 6. Original classification of the 70 stations dataset (Kohonen's algorithm).

\begin{tabular}{|c|c|c|c|c|c|}
\hline No & Name & Longitude & Latitude & $\begin{array}{c}\text { Kohonen } \\
\text { pseudo-coordinates }\end{array}$ & Group \\
\hline 1 & Chapotami & 477544 & 3848682 & $X=2, Y=2$ & 3 \\
\hline 2 & Diarizos & 474358 & 3854867 & $X=0, Y=2$ & 2 \\
\hline 3 & Xeros & 467799 & 3857116 & $X=3, Y=0$ & 4 \\
\hline 4 & Ezousa & 461052 & 3858615 & $X=3, Y=0$ & 4 \\
\hline 5 & Geroskipou & 448871 & 3850556 & $X=0, Y=2$ & 2 \\
\hline 6 & Mavrokolympos & 448308 & 3859177 & $X=2, Y=2$ & 3 \\
\hline 7 & Pegeia & 441749 & 3860864 & $X=0, Y=0$ & 1 \\
\hline 8 & Avgas & 441749 & 3866299 & $X=2, Y=2$ & 3 \\
\hline 9 & Akamas & 436877 & 3876231 & $X=0, Y=2$ & 2 \\
\hline 10 & Agios Ioannis & 441937 & 3875294 & $X=3, Y=0$ & 4 \\
\hline 11 & Chrysochou & 452994 & 3867423 & $X=0, Y=0$ & 1 \\
\hline 12 & Makounta & 456180 & 3878480 & $X=0, Y=0$ & 1 \\
\hline 13 & Xeros & 461427 & 3886539 & $X=2, Y=2$ & 3 \\
\hline 14 & Agios Theodoros & 465363 & 3891412 & $X=2, Y=2$ & 3 \\
\hline 15 & Katouris & 469486 & 3888975 & $X=3, Y=0$ & 4 \\
\hline 16 & Pyrgos & 469861 & 3882791 & $X=0, Y=2$ & 2 \\
\hline 17 & Limnitis & 473421 & 3881854 & $X=3, Y=0$ & 4 \\
\hline 18 & Kampos & 477357 & 3883353 & $X=3, Y=0$ & 4 \\
\hline 19 & Xeros & 480730 & 3879605 & $X=0, Y=0$ & 1 \\
\hline 20 & Marathasa & 485603 & 3878480 & $X=2, Y=2$ & 3 \\
\hline 21 & Kargotis & 490288 & 3873608 & $X=2, Y=2$ & 3 \\
\hline 22 & Atsas & 492912 & 3879605 & $X=0, Y=2$ & 2 \\
\hline 23 & Elia & 499096 & 3877543 & $X=2, Y=2$ & 3 \\
\hline 24 & Xeros & 499471 & 3889538 & $X=3, Y=0$ & 4 \\
\hline 25 & Serrachis & 514651 & 3885977 & $X=3, Y=0$ & 4 \\
\hline 26 & Aloupos & 506968 & 3903218 & $X=0, Y=2$ & 2 \\
\hline 27 & Kormakitis & 497972 & 3908841 & $X=3, Y=0$ & 4 \\
\hline 28 & Livera & 500221 & 3913151 & $X=3, Y=0$ & 4 \\
\hline 29 & Panagra & 508092 & 3908653 & $X=3, Y=0$ & 4 \\
\hline 30 & Lapithos & 517837 & 3910153 & $X=3, Y=0$ & 4 \\
\hline 31 & Kazafani & 532830 & 3907716 & $X=3, Y=0$ & 4 \\
\hline 32 & Klepini & 545199 & 3907904 & $X=3, Y=0$ & 4 \\
\hline 33 & Kalograia & 557193 & 3911090 & $X=3, Y=0$ & 4 \\
\hline 34 & Akanthou & 567126 & 3915025 & $X=0, Y=2$ & 2 \\
\hline 35 & Flamoudi & 577808 & 3917274 & $X=0, Y=2$ & 2 \\
\hline 36 & Potamoudia & 587929 & 3921585 & $X=3, Y=0$ & 4 \\
\hline 37 & Platanisso & 600298 & 3927207 & $X=3, Y=0$ & 4 \\
\hline 38 & Aigialousa & 608731 & 3933204 & $X=3, Y=0$ & 4 \\
\hline 39 & Rizokarpason & 624661 & 3941075 & $X=3, Y=0$ & 4 \\
\hline 40 & Ap. Antreas & 634031 & 3943699 & $X=3, Y=0$ & 4 \\
\hline 41 & Galinoporni & 618476 & 3932454 & $X=3, Y=0$ & 4 \\
\hline 42 & Lythragkomi & 606482 & 3924958 & $X=3, Y=0$ & 4 \\
\hline 43 & Koma tou Gialou & 598236 & 3920835 & $X=3, Y=0$ & 4 \\
\hline 44 & Komi & 591489 & 3915587 & $X=3, Y=0$ & 4 \\
\hline 45 & Trikomo & 582681 & 3911090 & $X=3, Y=0$ & 4 \\
\hline 46 & Pediaios & 538078 & 3893848 & $X=2, Y=2$ & 3 \\
\hline 47 & Kryos & 566189 & 3902844 & $X=2, Y=2$ & 3 \\
\hline 48 & Kalamulli & 574622 & 3908091 & $X=2, Y=2$ & 3 \\
\hline 49 & Ag. Sergios & 577434 & 3898346 & $X=3, Y=0$ & 4 \\
\hline
\end{tabular}


Table 6. cont.

\begin{tabular}{|l|l|c|c|c|c|}
\hline No & Name & Longitude & Latitude & $\begin{array}{c}\text { Kohonen } \\
\text { pseudo-coordinates }\end{array}$ & Group \\
\hline 50 & Gialias & 544450 & 3881292 & $\mathrm{X}=2, \mathrm{Y}=2$ & 3 \\
\hline 51 & Ammochostos & 575747 & 3883353 & $\mathrm{X}=3, \mathrm{Y}=0$ & 4 \\
\hline 52 & Liopetri & 581182 & 3873046 & $\mathrm{X}=3, \mathrm{Y}=0$ & 4 \\
\hline 53 & Voroklini & 556069 & 3873608 & $\mathrm{X}=3, \mathrm{Y}=0$ & 4 \\
\hline 54 & Aradippou & 549884 & 3870047 & $\mathrm{X}=3, \mathrm{Y}=0$ & 4 \\
\hline 55 & Larnaka salt lakes & 553633 & 3862176 & $\mathrm{X}=3, \mathrm{Y}=0$ & 4 \\
\hline 56 & Treminthos & 540701 & 3866861 & $\mathrm{X}=3, \mathrm{Y}=0$ & 4 \\
\hline 57 & Pouzis & 544824 & 3857116 & $\mathrm{X}=3, \mathrm{Y}=0$ & 4 \\
\hline 58 & Xeros & 539577 & 3853180 & $\mathrm{X}=3, \mathrm{Y}=0$ & 2 \\
\hline 59 & Pentaschoinos & 530956 & 3858990 & $\mathrm{X}=0, \mathrm{Y}=2$ & 2 \\
\hline 60 & Maroni & 528332 & 3852056 & $\mathrm{X}=0, \mathrm{Y}=2$ & 2 \\
\hline 61 & Vasilikos & 521211 & 3852805 & $\mathrm{X}=0, \mathrm{Y}=2$ & 2 \\
\hline 62 & Argaki tou Pyrgou & 516900 & 3845684 & $\mathrm{X}=0, \mathrm{Y}=2$ & 3 \\
\hline 63 & Germasogeia & 507905 & 3853368 & $\mathrm{X}=2, \mathrm{Y}=2$ & \\
\hline 64 & Ag. Athanasios & 504531 & 3842498 & $\mathrm{X}=2, \mathrm{Y}=2$ & \\
\hline 65 & Garyllis & 499471 & 3846621 & $\mathrm{X}=3, \mathrm{Y}=0$ & 3 \\
\hline 66 & Akrotiri & 497035 & 3835001 & $\mathrm{X}=3, \mathrm{Y}=0$ & 4 \\
\hline 67 & Kouris & 492912 & 3856179 & $\mathrm{X}=3, \mathrm{Y}=0$ & 4 \\
\hline 68 & Sotira & 486915 & 3839312 & $\mathrm{X}=2, \mathrm{Y}=2$ & 4 \\
\hline 69 & Avdimou & 479418 & 3842685 & $\mathrm{X}=0, \mathrm{Y}=0$ & 3 \\
\hline 70 & Pissouri & 471547 & $\mathrm{X}=2, \mathrm{Y}=2$ & 1 \\
\hline
\end{tabular}

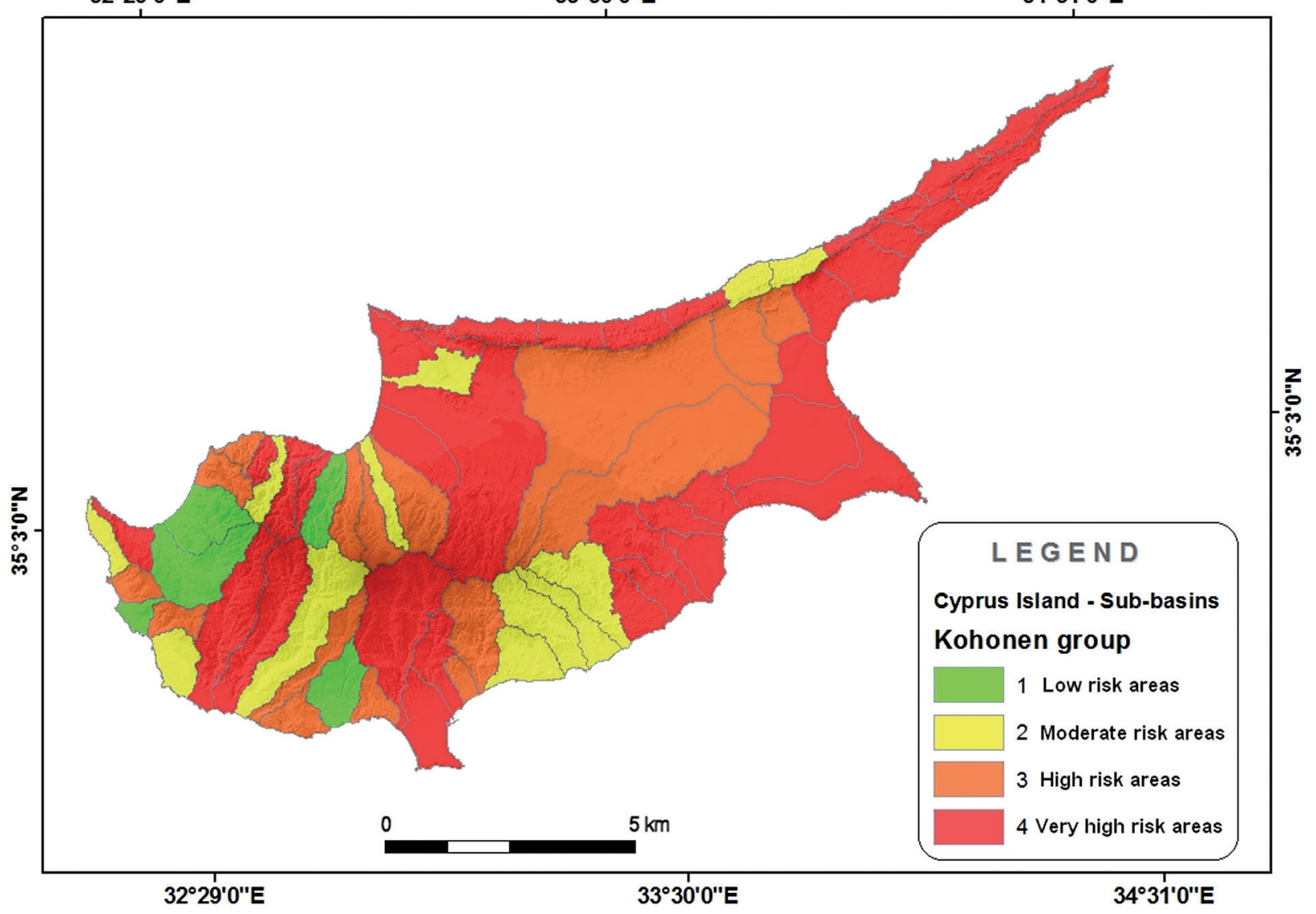

Fig. 3. Map of Cyprus with risk groups. 
will provoke important questions and insights. This provides opportunities and challenges on how to efficiently and effectively manage these data for new uncoverings. Unsupervised learning algorithms, which is the process of analyzing data without distinguishing dependent and independent variables and summarizing them into useful information and patterns, is of huge importance in bioinformatics. With more and different sources of data, it requires sophisticated computational analyses to study them. Unsupervised learning techniques can be used to undertake these challenging and interesting computational problems (Baird et al. 2008).

Based on Kohonen's algorithm we presented a method for regional hazard assessment. The results have shown that such analyses are promising with respect to larger regions and may serve as an input for regional-scale risk and vulnerability analyses.

\section{References}

Baird D., Rubach M., Van den Brinkt P., 2008. Trait-based ecological risk assessment (TERA): The new frontier? Integrated Environmental Assessment and Management 4(1): 2-3.

Birkmann J., Cardona O., Carreño M., Barbat A., Pelling M., Schneiderbauer S., Kienberger S., Keiler M., Alexander D., Zeil P., Welle T., 2013. Framing vulnerability, risk and societal responses: the MOVE framework. Natural Hazards 67(2): 193-211.

Cutter S., Mitchell J., Scott M., 2000. Revealing the Vulnerability of People and Places: A Case Study of Georgetown County, South Carolina. Annals of the Association of American Geographers 90(4): 713-737.

FEMA, 1997. Multi-hazard Identification and Risk Assessment. Government Printing Office, Washington. http:/ / www.fema.gov/pdf/fhm/mhira-in.pdf. Accessed 3 March 2014.

Field C., Barros V., Dokken D., Mach K., Mastrandrea M., Bilir T., Chatterjee M., Ebi K., Estrada Y., Genova R., Girma B., Kissel E., Levy A., MacCracken S., Mastrandrea P., White L. (eds)., 2014. Climate Change 2014: Impacts, adaptation, and vulnerability. Cambridge University Press, Cambridge.

Fuchs S., 2009. Susceptibility versus resilience to mountain hazards in Austria - Paradigms of vulnerability revisited. Natural Hazards and Earth System Sciences 9(2): 337-352.

Fuchs S., Kuhlicke C., Meyer V., 2011. Editorial for the special issue: vulnerability to natural hazards - the challenge of integration. Natural Hazards 58(2): 609-619.
Govindaraju R., Rao A. (eds)., 2000. Artificial neural networks in hydrology. Springer, Dordrecht.

IBM, 2011. SPSS Modeler 14.2 Modeling Nodes. IBM Corporation.

Kaufman, L. Rousseeuw, P., 2005. Finding groups in data: An introduction to cluster analysis. John Wiley and Sons, USA.

Kohonen T., 1982. Self-Organized Formation of Topologically Correct Feature Maps. Biological Cybernetics 43(1): 59-69.

Kuhlicke C., 2013. Resilience: a capacity and a myth: findings from an in-depth case study in disaster management research. Natural Hazards 67(1): 61-76.

Kumpulainen S., 2006. Vulnerability Concepts in Hazard and Risk Assessment. Geological Survey of Finland, Special Paper 42: 65-74.

Kurgan L., Cios K., 2001. Discretization Algorithm that Uses Class-Attribute Interdependence Maximization. In: Proceedings of the 2001 International Conference on Artificial Intelligence (IC-AI 2001), Las Vegas, Nevada.

Menoni S., Molinari D., Parker D., Ballio F., Tapsell S., 2012. Assessing multifaceted vulnerability and resilience in order to design risk-mitigation strategies. Natural Hazards 64(3): 2057-2082.

OAS - Dept. of Regional Development and Environment, 1991. Chapter 6 - Multiple Hazard Mapping. In: Primer of Natural Hazard Management in Integrated Regional Development Planning.

Papathoma-Köhle M., Kappes M., Keiler M., Glade T., 2011. Physical vulnerability assessment for alpine hazards: state of the art and future needs. Natural Hazards 58(2): 645-680.

Parry M., Canziani O., Palutikof J. (eds)., 2007. Climate change 2007. Impacts, adaptation and vulnerability: Working Group II contribution to the Fourth Assessment Report of the Intergovernmental Panel on Climate Change. Cambridge University Press, Cambridge.

Ratanamahatana C., 2003. CloNI: Clustering of $\sqrt{ } \mathrm{N}$-Interval discretization. In: Proceedings of the $4^{\text {th }}$ International Conference on Data Mining Including Building Application for CRM \& Competitive Intelligence, Rio de Janeiro, Brazil.

Stocker T., Qin D., Plattner G., Tignor M., Allen S., Boschung J., Nauels A., Xia Y., Bex V., Midgley P. (eds)., 2013. Climate change 2013: The physical science basis. Contribution of Working Group I to the Fifth Assessment Report of the Intergovernmental Panel on Climate Change. Cambridge University Press, Cambridge.

UN/ISDR, 2015. Sendai Framework for Disaster Risk Reduction 2015-2030. United Nations, Geneva

Varnes D., 1984. Landslide Hazard Zonation: A review of Principles and Practice. United Nations Educational Scientific and Cultural, USA.

Water Development Department. http://www.moa.gov. cy/moa/wdd/Wdd.nsf/index_en/index_en?OpenDocument

WGS - Word Geodetic System, 1984. National Geospatial - Intelligence Agency. https:/ / www1.nga.mil

Zachariadis T., 2012. Climate Change in Cyprus: Impacts and Adaptation Policies. Cyprus Economic Policy Review 6(1): 21-37. 